\title{
Editorial
}

\section{ECAM is waiting for eCAM}

\section{Edwin L. Cooper}

\author{
Laboratory of Comparative Neuroimmunology, Department of Neurobiology, David Geffen School of Medicine \\ at UCLA, University of California, Los Angeles, CA 90095-1763, USA
}

To wait is to live. Every aspect of our existence requires, demands and includes waiting. We wait for our research grants to be funded, our manuscripts to be accepted. For those of us who are on the way up, we wait to be promoted based on our scholarly involvement. Some of us, in fact, most of us are professors of various ranks and disciplines in universities throughout the world. Regardless of rank, we must also wait for responses (favorable we hope) from our students (mostly medical) who we anticipate will submit clear and objective polite comments concerning merits of our teaching efforts. We expect the same from referees of our manuscripts. Thus we all wait.

Waiting has permeated other areas, perhaps less tangible to us as biomedical researchers. There is the well-known theatre piece of Samuel Beckett: 'Waiting for Godot' which emphasizes a philosophical (existentialist) view of waiting connected to our living. Closer to home, Azumi et al. (1) even use this theme of 'Waiting for Godot' in a search for molecular linkages between the immune systems of invertebrate animals (protochordates are our nearest ancestors) and vertebrates. Thus, the pervasiveness of waiting always includes that which may be uncertain and may be accompanied by either the thrill and/or dread of waiting. Then moving closer to biomedical research before the invertebrate and vertebrate connection, 'Waiting for the End' by Niels K. Jerne (2) prefaces the then current state of immunology in advance of network theory and then clonal selection that of course we know as a Darwinian corollary. Both Beckett and Jerne, Nobel Laureates, poles apart, focused on waiting from the point of view of two widely different disciplines. There is even a hint of this theme in one of the many serious essays of Janeway (3) in relation to immunology and the asymptote, a line or curve that approaches

\footnotetext{
For reprints and all correspondence: Edwin L. Cooper, $\mathrm{PhD}, \mathrm{ScD}$, Distinguished Professor, Laboratory of Comparative Neuroimmunology, Department of Neurobiology, David Geffen School of Medicine at UCLA, University of California, Los Angeles, CA 90095-1763, USA. Tel: +1-310825-9567; Fax: +1-310-825-2224; E-mail: cooper@mednet.ucla.edu
}

a given curve arbitrarily close. And even more recently we recognize an extension of this direction. There is an attempt to solidify years of grappling with invertebrate immune systems and understanding signaling so essential for initiating an immune response beginning with the perception and reception of an antigen, and its fit to a proper receptor $(4,5)$.

Our entry into this debate of course refers to TOLL, one of the prominent pathways that explain the intimacy of linkages of early mechanisms of invertebrate innate immune systems with those of vertebrates-leaving less of a schism than we would have thought existed during the 19th century. This was an incredibly unique period in biology when Metchnikoff destroyed the prevailing monolith that shrouded immunology but dividing us into the cellular and humoral camps (6). And of course he accomplished this coup following enormous persistence using evidence derived from the observation of phagocytosis in marine invertebrates. Just think, simple observations of innate responses in invertebrates changed the very course of immunology and there is promise of invertebrates moving us into other directions of even more clinical relevance $(5,7)$.

Signaling in the organism especially in the immune system through the TOLL pathway is indeed crucial to understanding how the immune system works at the cellular level in humans. Animal models have been one current subject upon which $e C A M$ has focused. Having just returned from active participation at the 13th EFIS (European Federation Immunological Societies: Symposium on Signaling, Balaton, Hungary), I am particularly eager to draw our reader's attention to this subject of signaling as it could relate to CAM $(8,9)$. For this would widen the boundaries of $e C A M$ and increase its depth (10).

Why is ECAM waiting for $e C A M$ ? In our quest to raise the standards of CAM we are searching for evidence. Now at the completion of Volume 2, where are we? eCAM has covered all aspects of research that require evidence from representatives of every group in the animal kingdom (invertebrates and vertebrates). And the material presented concerning

(C) The Author (2005). Published by Oxford University Press. All rights reserved.

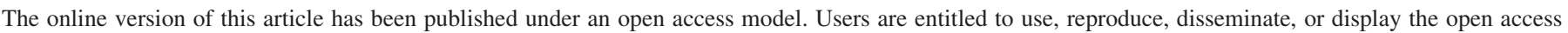

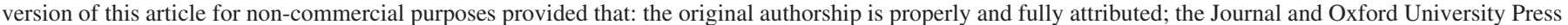

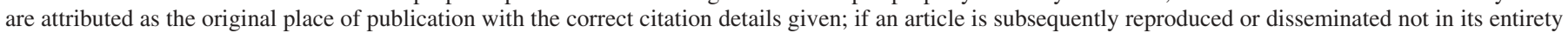
but only in part or as a derivative work this must be clearly indicated. For commercial re-use, please contact journals.permissions@oxfordjournals.org 
invertebrates in my opinion holds enormous promise for the following reasons. First, invertebrates have survived millions of years partly due to their capacity to reproduce and to their amazing capacity to synthesize and secrete protective molecules, especially those species that are sessile and unable to move and therefore dodge the attacks by territorial predators. This includes the sponges, echinoderms and the protochordates. However, all invertebrates do produce these molecules and they all are not necessarily sessile. Second, we believe that $e C A M$ has so far been balanced in its publications that seek a broad approach to the problem of creating an evidence base. In my opinion, however, $e C A M$ ever so young, still needs to include more clinical papers and that is why CAM is waiting for $e C A M$. This should come in due course since from our birth we have been listed in PubMed and now retroactive to Volume 1 an early listing in ISI, charting us on the road to an impact factor.

How long will we wait and will the nature of submissions of high quality require prolonged waiting? What is our formula for $e C A M$ so that we can diminish the time that we are waiting for CAM and clinical relevance? First, we can look at what we have published in an attempt to showcase $e C A M$ as a journal that publishes work of high quality and relevance to CAM. Second, although the first point of my editorial emphasizes waiting as inescapable, there should be another formula that will lessen the time that CAM is waiting for $e C A M$. What will lessen the waiting time for $e C A M$ to deliver credible CAM using the golden pyramid of Goldrosen and Strauss (11) as it pertains to increasing the quality of CAM publications? Although emphasizing immunology, the formula is applicable to any discipline or disease as long as biomedical researchers have the patience and resources to delve deeper and to become rigorous in their analyses.

At the heart of evidence are ideas. In the first part of his lecture series in $e C A M$, Alex Hankey (12) stresses the importance of the role of the development of theory in the advancement of evidence-based CAM, proposing that CAM modalities can stimulate new approaches to biological regulation that, if successfully developed, could result in a major paradigm shift in both biology and medicine, which will benefit all interested parties: consumers, health professionals, scientists, institutions and governments. And in our third issue of the year, Carlo Ventura (10), urging us to see CAM in a new light, writes of the subtle entanglement among different CAM systems, suggesting that CAM modalities may deeply affect both the signaling and transcriptional level of cellular homeostasis. He closes with the proposal that functional genomics and proteomics and the comprehension of the cell signaling networks may substantially contribute to the development of a molecular evidence-based CAM. Jose Olalde Rangel's (13) lecture series takes us step by step through the systemic theory from an explanation of the existence of disease to clinical evidence of its efficacy. He proposes that modern biophysics may provide the long sought explanation that bridges the abyss between the East and West as is illustrated symbolically on the cover of $e C A M$ by the woodblock print of Hiroshige.
In our search for inclusion of clinical papers, we understand that the great economic resources required to reach the top of the aforementioned golden pyramid are not always available. With lack of funding, again clinicians and scientists are forced to wait. In this case, the waiting period could be a time to develop hypotheses to explain the results that have been achieved in individuals and trials conducted lower on the golden pyramid. This is due to the lack of resources for randomized control trials or for myriad other reasons that abound in CAM such as the lack of an appropriate placebo. Some of the greatest discoveries of science have occurred when a scientific mind has wandered out of the daily clinical world or laboratory and into nature, where similar phenomena may be found that lead to radical discovery. A classic example of this is Michael Zasloff's discovery of magainins and other antimicrobial agents of animal origin (14). Hypotheses could connect clinicians with basic scientists and lead to the formation of a carefully laid evidence base. The ideas that come in the waiting will create bridges between previously unconnected fields of CAM, as well as between basic and clinical science, when working together (with funding) could quickly make the golden pyramid a reality.

\section{References}

1. Azumi K, De Santis R, De Tomaso A, Rigoutsos I, Yoshizaki F, Pinto MR, et al. Genomic analysis of immunity in a Urochordate and the emergence of the vertebrate immune system: 'waiting for Godot'. Immunogenetics 2003;55:570-81.

2. Jerne NK. Waiting for the End. Cold Spring Harb Symp Quant Biol 1967;32:591-603.

3. Janeway CA Jr. Approaching the asymptote? Evolution and revolution in immunology. Cold Spring Harb Symp Quant Biol 1989;54:1-13.

4. Engelmann P, Cooper EL, Nemeth P. Anticipating innate immunity without a TOLL. Mol Immunol 2005;42:931-42.

5. Cooper EL. Bioprospecting: a CAM frontier. Evid Based Complement Alternat Med 2005;2:1-3.

6. Cooper EL, Kauschke E, Cossarizza A. Digging for innate immunity since Darwin and Metchnikoff. Bioessays 2002;4:319-33.

7. Muller WE, Schroder HC, Wiens M, Perovic-Ottstadt S, Batel R, Muller IM. Traditional and modern biomedical prospecting: part II-the benefits: approaches for a sustainable exploitation of biodiversity (secondary metabolites and biomaterials from sponges). Evid Based Complement Alternat Med 2004;1:133-44.

8. Kasai H, He LM, Kawamura M, Yang PT, Deng XW, Munkanta M, et al. IL-12 production induced by Agaricus blazei fraction $\mathrm{H}(\mathrm{ABH})$ involves toll-like receptor (TLR). Evid Based Complement Alternat Med 2004;1: 259-67.

9. Qin B, Nagasaki M, Ren M, Bajotto G, Oshida Y, Sato Y. Gosha-jinki-gan (a herbal complex) corrects abnormal insulin signaling. Evid Based Complement Alternat Med 2004;1:269-76.

10. Ventura C. CAM and cell fate targeting: molecular and energetic insights into cell growth and differentiation. Evid Based Complement Alternat Med 2005;2:277-83.

11. Goldrosen MH, Strauss SE. Complementary and alternative medicine: assessing the evidence for immunological benefits. Nat Rev Immunol 2004;4:912-21.

12. Hankey A. CAM modalities can stimulate advances in theoretical biology. Evid Based Complement Alternat Med 2005;2:5-12.

13. Olalde Rangel JA. The systemic theory of living systems and relevance to CAM: the theory (part III). Evid Based Complement Alternat Med 2005;2: 267-75.

14. Jacob L, Zasloff M. Potential therapeutic applications of magainins and other antimicrobial agents of animal origin. Ciba Found Symp 1994;186: 197-216. 


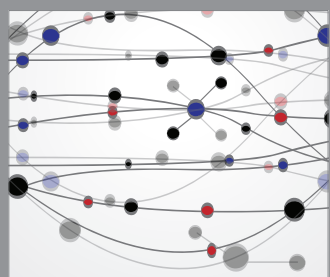

The Scientific World Journal
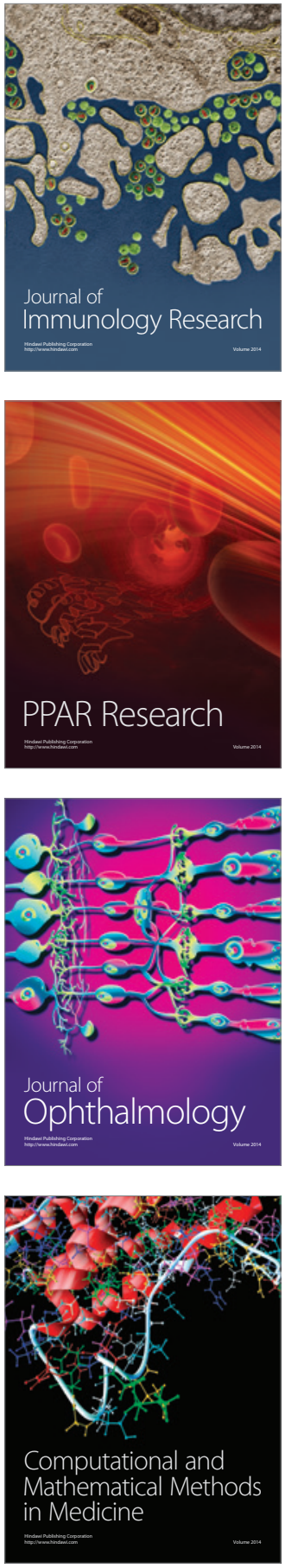

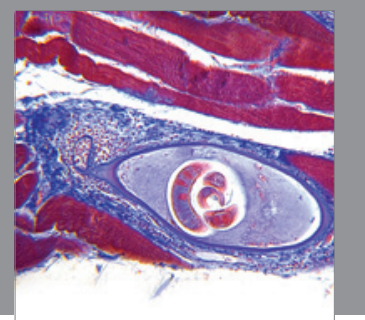

Gastroenterology

Research and Practice
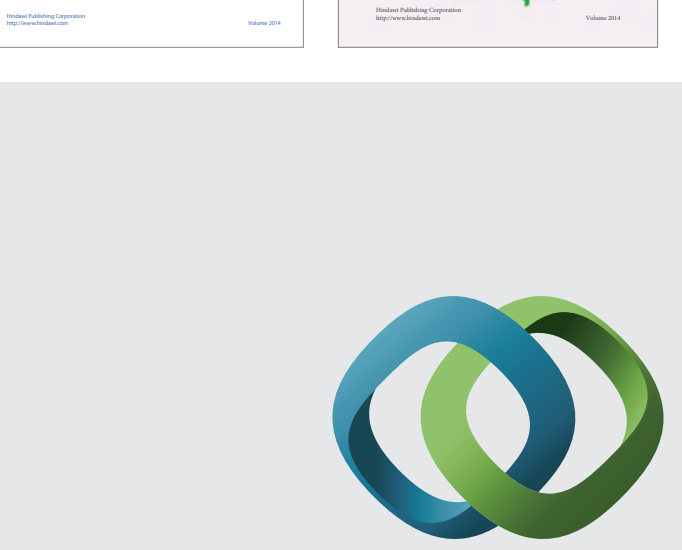

\section{Hindawi}

Submit your manuscripts at

http://www.hindawi.com
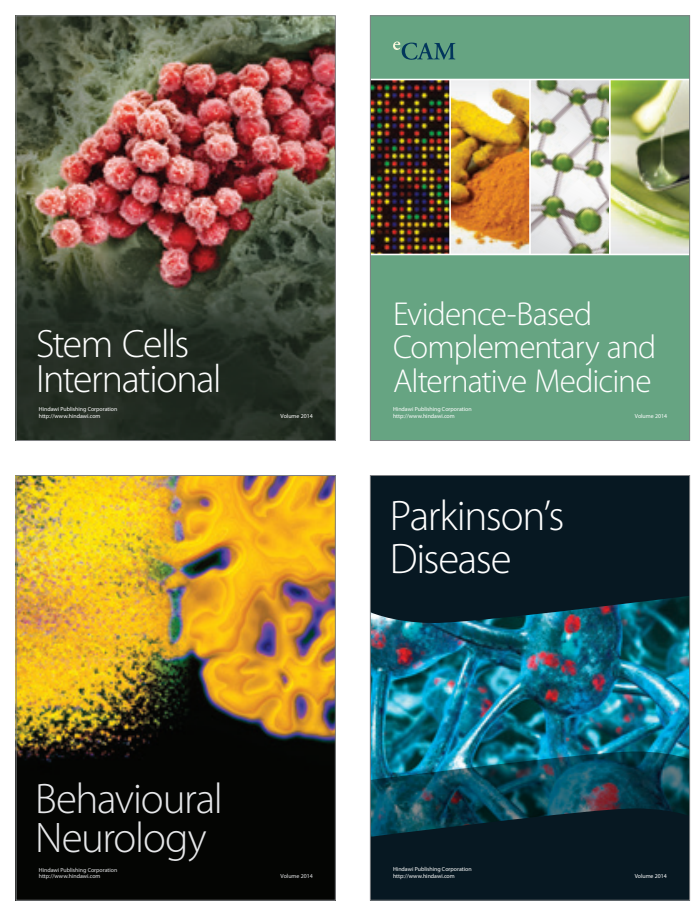

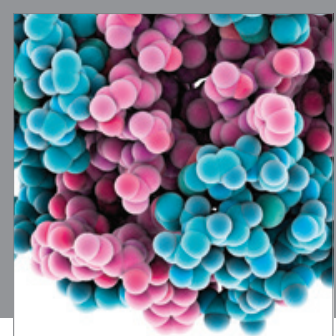

Journal of
Diabetes Research

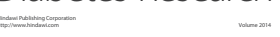

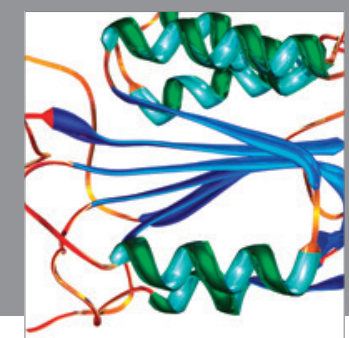

Disease Markers
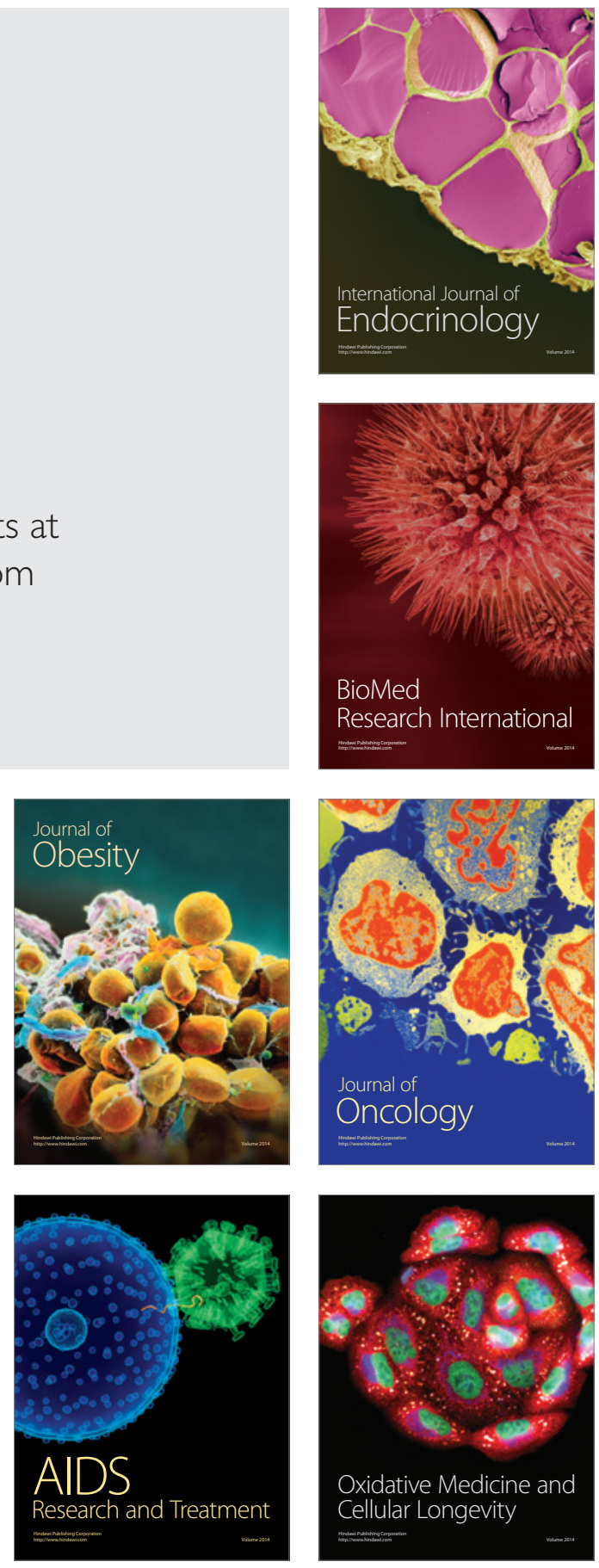